\title{
An Analysis of Drug Abuse Networking in Pakistan
}

\author{
MUHAMMAD RAFIQ
}

\section{INTRODUCTION}

There are three principal reasons for undertaking the present paper. First, although all the dimensions of diffusion of drug abuse are still uncertain and the existence and extent of Drug Abuse Networking (DAN) is certainly not the only factor determining the likelihood of the spread of drug abuse. Nevertheless, one of the prime modes of its spread is through DAN. The extent of DAN and the diffusion of drug abuse in society are closely related to each other [Brook, Nomura and Cohen (1989, 1989a, 1992); Kornhauser (1978); Elliott, Huizinge and Dunford (1983); Delemarre (1993)]. Second, the network analysis provides an important instrumental element to deal with social problems and to uncover the information for intervention in specific groups of the community for the well-being of its members [Uehara (1990); Wellman and Scott (1990); Brook, Nomura, and Cohen (1980); Coombs (1973); Thompson (1973); Eggert, Thompson, Herting, Nicholas and Dicker (1994); Gould (1991)]. Last, the issues of DAN's dynamics and its control have received little attention in literature relevant to Pakistan or elsewhere. It is also considered important from the policy point of view to determine the dynamics of DAN in Pakistan on the basis of experimental research. ${ }^{1}$ It is hoped that this paper will help in the attainment of these goals. It addresses the subject from different perspectives, but the major aim is to help develop and establish methodologies in the context of Pakistan. Such research may help those involved in making the policies and in controlling the diffusion of drug abuse in Pakistan.

In recent years, a theoretical framework pertaining to the DAN has emerged, with the help of which the background information of drug abusers may be organised to categorise similarities and differentials and, most importantly, to identify the key Islamabad.

Muhammad Rafiq is Deputy Chief Programmer, Pakistan Institute of Development Economics,

Author's Note: I am grateful to Dr Muhammad Ali Chaudhry, Dr Muhammad Irfan and Dr Naushin Mahmood for useful suggestions. I also acknowledge typing assistance provided by Mr Zamir Hussain Shah.

${ }^{1}$ There are several studies [Habib (1984); Hussain (1984); Jaffari (1984); Khan (1982); Pakistan Narcotics Control Board (1982, 1986, 1988, 1993)] regarding the pattern of drug abuse in Pakistan but there is little evidence about DAN. 
relationships between the variables that determine the course of drug abuse among individuals and the patterns observed in the community of people. ${ }^{2}$ The factors that determine the dynamics of DAN can be examined with reference to the major socioeconomic components of DAN. How these factors vary in human communities and how each component influences DAN requires detailed analysis. This paper presents an analysis to look for the variation of such factors among the drug abusers and the way they influence the DAN.

\section{METHODOLOGY}

The formation of DAN is a phenomenon in which the role of individual decision-making in establishing DAN is dependent largely on different exogenous factors. ${ }^{3}$ Such a phenomenon may take place through social factors, or by spatial indicators, or because of economic conditions, or through a combination of these factors. To test a relationship between DAN and such factors, we proceed as follows.

A drug abuser will be identified as a member of DAN (disconnected or connected) if the drug abuser has a friend or has friends who abuse drugs. ${ }^{4}$ After classification of the respondent as a member of DAN, a multivariate analysis is undertaken to determine the dynamics of DAN using social and economic variables. DAN is measured as a dummy-dependent variable formed as follows:

DAN $=1$ if the drug abuser is currently a member of DAN, and $=0$ otherwise

Because of the binary nature of the dependent variable, the logistic regression is used which estimates the probability of occurrence of an event [Yamaguchi and Kandel (1987); Morgan and Teachman (1988); Hosmer and Lemeshow (1989)]. The model can be written as

$$
\operatorname{Prob}(\mathrm{DAN}=1)=\frac{1}{1+e^{=z}} \quad \ldots \quad \ldots \quad \ldots
$$

${ }^{2}$ Strang and Tuma (1993) developed a diffusion model and applied it to perform sociometric analysis of the decision to employ tetracycline as a prescription drug by physicians. It was found that network centrality and local structure of influence based on cohesive relation and structural equivalence were all shown to enhance the diffusion of tetracycline. Though this is not a drug abuse study, but a similarity exists in the work undertaken here.

${ }^{3}$ Bronfenbrenner (1979) has termed these factors as settings. Many settings constitute a microsystem through interactions. These microsystems in turn form a larger system, which plays a decisive role in development of a particular event taking place. Huckfeldt (1983) and Wilson and Herrnstein (1985) have found that neighbourhood factors influence the choice of friend and peer activity.

${ }^{4}$ Suppose there are three drug abusers, namely, A, B, and C. If A is a friend of B, B is a friend of C, and $\mathrm{C}$ is a friend of A, then the network will be called a connected network, otherwise it is a disconnected network. For details about connected and disconnected networks, see Harary, Norman and Cartwright (1965); Kemeny and Snell (1960); Friedkin (1991) and Yamagishi and Cook (1988). 
Where Prob is the underlying probability of drug abuser falling in DAN which is assumed to be completely determined by $Z$, which, in turn, is a linear combination of the following form:

$$
Z=\beta_{0}+\beta_{1} X_{1}+\beta_{2} X_{2}+\ldots \ldots+\beta_{p} X_{p} \quad \ldots \quad \ldots \quad \ldots \quad \ldots
$$

Where

$X_{1}, X_{2}, \ldots . X_{p}$ are exogenous variables.

$\beta_{\mathrm{o}}$ is intercept.

$\beta_{1}, \beta_{2}, \ldots . \beta_{\mathrm{p}}$ are coefficients of exogenous contribution for the vector of individual's decision.

$e$ is the base of the natural logarithms.

The probability of the event not occurring is estimated as

$$
\operatorname{Prob}(D A N=0)=1-\operatorname{Prob}(D A N=1) \quad \ldots \quad \ldots
$$

The logit as opposed to proportions gives predictions or coefficients which have positive and negative signs, and indicates the magnitude of the increment in the log-odds of DAN with a unit change in the explanatory variables. The parameters in Equation 2 are estimated using the maximum likelihood method, i.e., it is the coefficients that make our observed results most likely are selected. The effect of the explanatory variables on DAN is evaluated through the estimation of different models.

\section{THE DATA}

The present paper is based on the data drawn from The National Survey on Drug Abuse 1993 (NSDA). The sample of the survey consisted of 1000 respondents. The Survey generated information on the prevalence of drug abuse in Pakistan. Although the data on DAN in the survey was not sufficient to carry out an adequate analysis, it did contain satisfactory data on certain aspects. The description of the survey and the sampling methodology is given in the survey report.

\section{A Review of Survey Findings}

It is useful to begin with a brief review of the salient characteristics of the sample respondents summarised in Table 1. According to the survey, the most commonly abused drugs in the society are heroin, charas (cannabis), opium, bhang (a mixture of cannabis and water), and alcohol. It was found that 50.7 percent of the sample respondents abused heroin, 29.5 percent charas, and the remaining (19.8 percent) used opium, bhang, alcohol, and other drugs. ${ }^{5}$ The sample is predominantly

${ }^{5}$ The other category includes mandrax tranquiliser, opiates (pethidine, morphine, and soausigan), naswar (green tobacco), ganja (marijuana), hallucinogen(LSD), inhalants (petrol and paint), dhatoora (local name), and cough syrups, etc. 
Table 1 
urban, with only 35.4 percent of the respondents living in rural areas. Of the urban sample, 52.0 percent were heroin abusers, 28.8 percent were charas abusers, and 19.6 percent abusers belonged to other groups of drugs. The rural sample consisted of 48.3 percent heroin abusers, 30.8 percent charas abusers, and 20.9 percent were other-drugs abusers. Likewise, the survey consisted of 97.2 percent males and only 2.8 percent females. Out of the male respondents, 50.1 percent were heroin abusers, 30 percent were using charas, and the remaining 19.9 percent were other-drugs abusers.

In addition, the other characteristics of the sample show that 41.8 percent were single, 54.1 percent were married, and the remaining 4.1 were divorced, widowed, or separated. The average household size of the sample respondents is 8 family members. mean ago of respondents in the sample is 32.0 years. Mean age of urban and rural population is 31.7 and 32.6 years, respectively. Results show that heroin has come out as the most popular drug and charas as the second most popular drug in all segments of the population.

\section{MODEL ESTIMATES}

The estimated logit coefficients of the two models are reported in Table 2. Model 1 provides estimates for all of Pakistan and Model 2 relates to regions and provinces but is extended to include the variable regarding treatment facilities availed of by the drug abusers. The values of - 2LL, Model Chi Square, and Goodness of Fit of both models show that the variables included have very well explained the variation in drug abuse. Model chi-square statistics show that the models are a significant improvement over model of independents. Most of the coefficients appear to be significantly different from zero, 0.1 percent, 0.05 percent, and 0.001 percent level of significance, and are associated with valid signs. Variables like age, education, and unemployment emerge as the major determinants of DAN. Unemployment appears as a policy variable for controlling drug abuse in Pakistan which positively affects the log odds of DAN. The probability for the model is 0.988 which shows that a drug abuser of age 32 years and having household size 8 is predicted to fall in DAN. ${ }^{6}$ The probability of not being in DAN is 0.012 (that is, 1-0.988). Therefore, the odds of falling in DAN are 82.33 (that is, $0.988 / 0.012$ ), and the log of the odds is 4.4. Similarly, the probability of Model 2 is computed at 0.99. It is interesting to note that in both the models, relatively high probability of DAN is associated with numerous responses. The results are now discussed for each variable.

\section{Age}

Results in Table 2 indicate that the likelihood of being in DAN of younger drug

${ }^{6}$ In general, if the estimated probability of event is less than 0.5 , we predict the event will not occur. If it is greater than 0.5 , we predict that the event will occur. 
Table 2 
abusers is high. As the abuser gets older, the chances to be in DAN reduce. The negative coefficient $(-0.02)$ of almost the same magnitude in both models shows that the odds of falling in DAN are decreased by $0.98\left(\mathrm{e}^{-0.02}\right)$ as the age of the drug abuser increases by one year, other variables held constant. It suggests that the propensity to associate with DAN decreases with age. This is consistent with Pakistan's sociocultural context, where a joint family system is observed and the younger family members have less responsibilities.

\section{Household Size}

Since there were 41.8 percent unmarried respondents and since 71.8 percent of them were up to 30 years of age, resulting in limited information about the family of drug abusers, it was decided to include household size in the model as household environmental variable, which has turned up as one of the major determinants of DAN. The significant and positive coefficient ( 0.12 almost the same in both models) associated with it shows that if the size of a household increases by 1 member, the other variables in DAN do not change, the log odds of occurrence of event increase by 0.12 . It may thus be argued that as population increases, the diffusion of a trait like drug abuse also increases.

\section{Education}

Traditionally, the purpose of education has been to socialise humans and to serve as an agent of social reform [Busch-Rossnagel and Vance (1982)]. Beyond all functions, educational institutions as social systems are considered to have a major influence on personal and social development and provide new norms and innovations. Therefore, education should provide greater awareness and knowledge about the consequences of drug abuse. However, this is not confirmed in this study and the results are not in agreement with our expectations. The estimated coefficients in both models are 0.613 and 0.64 , respectively, which are positive and significant. These coefficients explain that when education of drug abuse changes from 0 to 1 , with other variables remaining constant, log odds of drug abuse for becoming member of DAN increases by 0.6 (1.8 odds). Hence Table 2 shows that education of respondents and DAN are strongly positively correlated. This analysis further provides a synthesis that some institutions may be a locus which initiates drug abuse. ${ }^{7}$ The results thus suggest that the most promising interventions are required in educational institutions to discourage drug abuse. $^{8}$

${ }^{7}$ Johnston (1973) reported that schools with student bodies smaller than 250 showed very low use of illegal drugs, whereas those with a student population exceeding 2,000 showed an exceptionally high rate of illicit drug use.

${ }^{8}$ This is in line with the findings of Minuchin and Shapiro (1983). 


\section{Unemployment}

There were many variables showing the socio-economic status of drug abusers, like occupation, employment, and income. All the variables were found to be correlated with each other. Among them, the unemployment variable was selected to be included in the model, keeping in view two points: (1) The variable of unemployment can be used as an instrument for intervention in the community; (2) the unemployment status of the drug abuser is used to analyse an economically depressed class. The significant positive signs of the coefficients (1.413 and 1.26) of unemployment in both models show that as drug abusers become unemployed, the log odds of drug abuse for falling in the DAN increase by 1.413. This finding also goes along with a study by Elliott, Huizinge, and Dunford (1983) and Kornhauser (1978). They stated that communities low in socioeconomic status, having less opportunities and large in populations, were associated with increasing drug use. At the macro level, employment is a powerful factor in economic growth and transformation, allowing a better utilisation of national human resources. Employment is a topical issue at present. Many countries including Pakistan face unprecedented challenges of unemployment. It has its own cost, with varied ramifications. Policies need to be designed to increase employment opportunities, and thereby the standard of living of the people, to control drug abuse.

\section{Treatment Services}

This variable was included in the model in terms of access of drug abusers to available treatment services in the region. The question was if the drug abuser ever tried to abstain from drug abuse and received the treatment facilities from NGOs, hospitals, and by medical doctors. There were not enough cases of those who received such services from NGOs. Therefore, it was decided to include hospital versus other treatment facilities in Model 2. It has been found that the services environment in the community affects the pattern of DAN negatively.

\section{Region of Residence}

Region of residence was included in Model 2 to capture the regional effect of community services on the extent of DAN being provided in urban areas. Urban areas have greater access to social services, easy approach to health facilities, and better supply of infrastructure. These may exert an influence on the behaviour and attitudes of drug abusers. The coefficient associated with this variable is insignificant; however, it affects the extent of DAN in the expected direction. 


\section{Provinces}

Dummy variables for the provinces of Sindh, the NWFP, and Balochistan were included in Model 2 to capture the regional and ethnic effects of respondents living in different provinces of Pakistan, and to see if a significant difference in DAN exists by different geographical and ethnic locations. The coefficients of the NWFP (1.8) and Sindh (0.75) are positive and significant, while they are negative and insignificant for Balochistan. This means that DAN is more commonly diffused in the NWFP and in Sindh than in the Punjab and Balochistan.

\section{REFERENCES}

Bronfenbrenner, U. (1979) The Ecology of Human Development: Experiment by Nature and Design. Cambridge, MA: Harvard University Press.

Brook, J. S., et al. (1992) Childhood Precursors of Adolescent Drug Use. A Longitudinal Analysis. Genetic, Social, and General Psychology Monographs 118:2.

Brook, J. S., C. Nomura, and P. Cohen (1989) A Network of Influences on Adolescence Drug Involvement: Neighborhood, School, Peer, and Family. Genetic, Social, and General Psychology Monographs 115:1 125-145.

Brook, J. S., C. Nomura, and P. Cohen (1989a) Prenatal, Perinatal, and Early Childhood Factors and Drug Abuse Involvement in Adolescence. Genetic, Social, and General Psychology Monographs 115:1 223-237.

Busch-Rossnagel, N. A., and A. K. Vance (1982) The Impact of the Schools on Social and Emotional Development. In B. B. Woman (ed.) Hand Book of Developmental Psychology, Englewood Cliffs, NJ: Prentice Hall. 452-467.

Coombs, Gary (1973) Networks and Exchange: The Role of Social Relationship in a Small Voluntary Association. Journal of Anthropological Research 29:2 96-113.

Delemarre-van-de-Waal-HA (1993) Environmental Factors Influencing Growth and Pubertal Development. International Workshop on Impact of the Environment on Reproductive Health. Copenhagen (Denmark), 30 Sep-4 Oct 1991. Environment Health Perspectives 101:2 39-44.

Eggert, L. L., E. A. Thompson, J. R. Herting, L. J. Nicholas, and B. G. Dicker (1994) Preventing Adolescent Drug Abuse and High School Dropout Through Intensive School-based Social Network Development Programme. American Journal of Health Promotion 8:3 202-215.

Elliott, D. S., D. Huizing, and F. W. Dunford (1983) Understanding Delinquency and Crime: A Longitudinal Study of Development Patterns and Conditions Leading to Criminal Behaviour. Unnpublished Manuscript, Behaviour Research Institute, Boulder, Co. 
Friedkin, Noah E. (1991) Theoretical Foundations for Centrality Measures. American Journal of Sociology 96:6 1478-1504.

Gould, Roger V. (1991) Multiple Networks and Mobilisation in The Paris Commune, 1871. American Sociological Review 56:6 716-729.

Habib, F. (1984) Psychological and Social Aspects of drug Addiction. Reflections on Drug abuse Proceedings of the workshop on Mass Media Orientation for the Prevention of Drug Abuse. Islamabad: Pakistan Narcotics Control Board. 57-80.

Harary, Frank, Robert Z. Norman, and Dorwin Cartwright (1965) Structural Models: An Introduction to the Theory of Directed Graphs. New York: Wily.

Huckkfeldt, R. L. (1983) Social Context, Social Network and Urban Neighbourhood: Environment Constraints on Friendship Choice. American Journal of Sociology 89:3 551-669.

Hussain, M. (1984) Some Facts About Drug Use which Mass Media may Use. Reflections on Drug Abuse-Proceedings of the Workshop on Mass Media Orientation for the Prevention of Drug Abuse. Islamabad: Pakistan Narcotics Control Board.

Jaffari, S. K. (1984) Drug Abuse Among Youth in Karachi. Proceedings of Mass Media Conference on Drug Abuse Prevention. Islamabad: Pakistan Narcotics Control Board.

Johnston, L. (1973). Drug and American Youth. Michigan: Institute of Social Research.

Khan, M. Z. (1982) Heroin Abuse in Karachi Proceedings of International Conference on Demand \& Supply of Opiates in Pakistan. Islamabad: Pakistan Narcotics Control Board.

Kemeny, John G., and J. L. Snell (1960) Finite Markov Chains. Princeton, N. J.: Van Nostrand.

Kornhauser, R. R. (1978) Social Sources of Delinquency. Chicago: Chicago University Press.

Pakistan Narcotics Control Board (1982) National Survey on Drug Abuse in Pakistan. Islamabad.

Pakistan Narcotics Control Board (1986) National Survey on Drug Abuse in Pakistan (Highlights) Islamabad.

Pakistan Narcotics Control Board (1988) National Survey on Drug Abuse in Pakistan Islamabad.

Pakistan Narcotics Control Board (1993) National Survey on Drug Abuse in Pakistan Islamabad.

Strang, David, and N. B. Tuma (1993) Spatial and Temporal Heterogeneity in Diffusion. American Journal of Sociology 99:3 614-639.

Thompson, R. A. (1973) A Theory of Instrumental Social Networks. Journal of Anthropological Research 29:4 244-265. 
Uehara, Edwina (1990) Dual Exchange Theory, Social Networks, and Informal Social Support. American Journal of Sociology 96:3 521-557.

Yamagishi, T., M. R. Gillmore, and Karen S. Cook (1988) Network Connection and the Distribution of Power in Exchange Networks. American Journal of Sociology 93:4 833-851.

Wellman, Barry and Scot Wortley (1990) Different Strokes from Different Floks: Community Ties and Social Support. American Journal of Sociology 96:3 558588.

Wilson, J. Q., and R. J. Herrnstein (1985) Crime and Human Nature. New York: Simon and Schuster. 


\section{Comments}

Drug abuse has never been an uncommon phenomenon in this part of the world. People have been found using or abusing different kinds of drugs, and they have somehow been tolerated by the society. The drug abusers, nevertheless, have been largely looked down upon by the society, but the practice has been continuing. The present situation of the drug abuse in Pakistan, however, is somewhat serious, and has grave consequences. Since late seventies, a new drug, namely Heroin, has come to the scene and its abuse has been on the increase. Conservative estimates of heroin addicts alone in the country put a figure around $2 \mathrm{Mn}$. The fact that its abuse has serious health hazards, and almost cripples the lives of the addicts, is sufficient to concern workers in human development and welfare, to look into the causes of its raped spread and seek the ways and means of putting a stop to its production and undertake rehabilitation exercises.

This paper is a good effort. Although such an exercise should, ideally, have been done by a psychologist; even a sociologist would have been preferable. But it seems that the PSDE does not have psychologists among its members, and the sociologists might have been assigned certain other jobs. Hence, please bear an economists' comments for a few minutes.

Let me come to the paper under discussion. As the title suggests, I had somehow expected detailed information and analysis on the pattern of drug abuse, the socioeconomic characteristics of the abuses, the mechanism of drug abuse networking, sources and modalities of drug supplies, and the suppliers and their networking. This expectation was carried further by the reading of the first few pages, and especially while going through the three principal reasons stated which seem to have prompted the author to undertake such an exercise.

The methodology adopted seems to be fairly suitable and the data-set based on the sample survey of 1,000 respondents is considered sufficient to respond to the stated aims of the study. But beyond that, I find a number of omissions and commissions. They are presented below for the consideration of the author.

Let us start with the data, its source, and different characteristics. Merely saying that the description of the survey and the sampling methodology is given in the survey report somehow irritates the reader. A few paragraphs on the sample selection, the survey methodology, the areas covered, and how the respondents were selected would have added to the usefulness of the paper and the consequent analysis. The analysis based on a survey of 1,000 respondents should in no way be taken to represent the whole country. The findings and conclusions drawn would not carry sufficient weight if they are meant for the country as a whole. The author may like to look into this observation. 
In the data section, a review of the survey findings as given in Tables 1 and 2 is used to elaborate the drug-wise demographic profile of drug abusers and the paradigm of DAN. Half of the respondents have been found to be abusing "heroin". Drug abuse seems to be neutral to matrimonial status but is heavily concentrated amongst the relatively younger population. Although the paper confirms the normally held belief that friends are the best motivators and even facilitators for drug abuse, yet further discussion based on Table 2 becomes somewhat irritating when percentages do not add up to 100 and in some cases are, instead, found to be as high as 180 percent. The justification given in footnote 8 surely loses its validity with such high distortions.

The author is advised to have another look at the data and try to do some necessary cleaning; otherwise his intentions to provide certain guidelines to the policymakers and drug enforcement agencies would not be accomplished. Similarly, he needs to have a look at certain other variables, such as the place of drug abuse, those introducing the drugs, and the high proportion of the miscellaneous elements. At least I failed to comprehend how a casual acquaintance can introduce one to drug abuse? The same is true of the conclusion drawn that "the level DAN is high and the society is dangerously exposed to further diffusion of drug abuse". One wonders how this has been concluded. It may also be pointed out that some figures in Table 2 do not correspond correctly to the write-up and the figures in the text. Take, for example, the mention of friends as the main source of exposing one to drugs, 86.6 percent, while the Table 2 provides a substantially smaller proportion for the same.

The conclusions of the paper seem to be simplistically drawn. These are: (i) as population increases, the diffusion of drug abuse also increases; and (ii) education and DAN are positively and strongly related. There is no mention of education as a variable in Table 2. Similar is the case of the strong relation between unemployment and drug abuse. This could be an important finding but should have been discussed more, especially the profile of the unemployed, the reasons and length of unemployment, and the educational levels and the training background.

This paper, somehow, does not fulfil the expectations laid down as its "principal aims". Moreover, insufficient and, at times, incorrect information has been provided. Similarly, important drug-related information is absent. We should ask: who are the drug abusers? What are their socio-economic characteristics? Why do they go for drug abuse? Who are the suppliers? What is the mechanism for drug supplies? What is the relationship of drug abuse of different kinds with its availability? And what are the policy implications? As a layman but a curious reader of the subject, I had expected some meaningful discussion on these variables. Unfortunately, this paper does not provide it. May be it is basically due to the data-set being used for this paper, as the author also indicates certain limitations. But it cannot be offered as an excuse.

Let me conclude with the appreciation of the author's work. This reading has added information on the subject and also raised certain worries. Drug abuse control by 
mere legislation and with growing unemployment would be a futile exercise. Policymakers are well advised to design comprehensive employment promotion and a manpower development policy with an active participation of the private sector and the NGOs. A blueprint to this effect is available in the Report of the National Manpower Commission. Moreover, for effective drug enforcement, active involvement of local social groups is needed.

Friedrich-Ebert-Stiftung,

Sabur Ghayur

Islamabad. 